\title{
Anti-KSP/Anti-VEGF siRNAs ALN-VSP02
}

National Cancer Institute

\section{Source}

National Cancer Institute. Anti-KSP/Anti-VEGF siRNAS ALN-VSPO2. NCI Thesaurus. Code C82391.

A lipid nanoparticle formulation containing two small interfering RNAs (siRNAs) for kinesin spindle protein (KSP) and vascular endothelial growth factor (VEGF) with potential antitumor activity. Upon intravenous administration, the siRNAs in KSP/VEGF siRNAs ALN-VSP02ALN bind to both KSP and VEGF messenger RNAs (mRNAs), preventing translation of KSP and VEGF proteins; this may result in growth inhibition of tumor cells that overexpress KSP and VEGF. VEGF and KSP are upregulated in many tumor cells and play an important role in tumor proliferation and survival. 